\title{
Mountain torque events in the Mediterranean
}

\author{
J. Egger ${ }^{1}$ and K. P. Hoinka ${ }^{2}$ \\ ${ }^{1}$ Meteorologisches Institut der Universität München, München, Germany \\ ${ }^{2}$ Institut für Physik der Atmosphäre, Deutsches Zentrum für Luft- und Raumfahrt, Oberpfaffenhofen, Germany
}

Received: 21 February 2007 - Revised: 23 May 2007 - Accepted: 24 May 2007 - Published: 28 June 2007

\begin{abstract}
Typical events of torques exerted by the Alps are analysed by correlating flow observations in the Mediterranean with these torques. More specifically, events with positive torques with respect to the "rotation axis" at $90^{\circ} \mathrm{E}$, $0^{\circ} \mathrm{N}$ in fall are selected. A trough forms above the western Mediterranean during such an event with a ridge in the west. A separate low pressure system is induced in the lee of the Alps which moves then eastward with the upper-level trough. A linear forecast equation based on potential temperature changes reveals that this Alpine "lee cyclone" is mainly due to warm air advection east of the trough. Precipitation is discussed as well.
\end{abstract}

\section{Introduction}

The Mediterranean is surrounded by impressive mountain ranges like, for example, the Alps and the Atlas mountains in the West, the Dinaric Alps in the center and the Taurus mountains in the East. All these massifs affect the baroclinic systems entering the Mediterranean basin from outside and, of course, also those leaving it (e.g. Alpert et al., 1990; Lionello et al., 2006). Although there does not exist a generally accepted parameter to measure the strength of this interaction, the mountain torques exerted during the passage of synoptic systems over a mountain massif provide a suitable measure of the intensity of this interaction (e.g. Egger and Hoinka, 2006). As is well known, the torque $T_{o}$ exerted by a mountain on the angular momentum of the atmosphere has three components, two equatorial ones $T_{o 1}, T_{o 2}$ and the axial component $T_{03}$ so that

$T_{o}=T_{o 1} i_{1}+T_{o 2} i_{2}+T_{o 3} i_{3}$.

where the basic unit vectors $\boldsymbol{i}_{\boldsymbol{i}}$ point from the Earth's center to the equatorial Greenwich point $\left(i_{1}: \lambda=0, \varphi=0\right)$, to $90^{\circ} \mathrm{E}$

Correspondence to: J. Egger

(j.egger@lrz.uni-muenchen.de) $\left(\boldsymbol{i}_{2}: \lambda=\pi / 2 ; \varphi=0\right)$ and to the North pole $\left(\boldsymbol{i}_{3} ; \varphi=\pi / 2\right)$. The axial torque

$T_{o 3}=-\int_{F} p_{s} \frac{\partial h}{\partial \lambda} d f$,

captures essentially the east-west surface pressure difference across the mountain where $\mathrm{h}$ is the topography, $p_{s}$ is the surface pressure and $F$ is an area covering the obstacle. In analogy, $T_{o 2}$ is calculated such that the point $\left(\lambda=90^{\circ} \mathrm{E} ; \varphi=0\right)$ is the related pole and pressure differences across the mountain are calculated moving cyclonically along "latitude circles" with respect to this pole. Assume a surface pressure distribution with a high (low) north (south) of the Alpine crest. In that case, both $T_{o 1}$ and $T_{o 3}$ are small while $T_{o 2}$ is negative with respect to the Alps. An inspection of the surface pressure maps related to Alpine lee cyclogenesis (e.g. Pichler and Steinacker, 1987) suggests that the Alps exert torques during such events. The approach of a cold front from the northwest and the concomitant pressure fall in the south imply a decrease of $T_{o 2}$. Hence, we choose $T_{o 2}$ as an appropriate new interaction parameter in order to capture this type of events. For that purpose, pressure, potential temperature, wind fields and precipitation as observed are regressed against the torque $T_{o 2}$. Note, however, that all available days enter in this analysis while lee cyclogenesis investigations are restricted to case studies. The observations are available in form of the ERA40 data set covering the period January 1958-December 2001. The analysis domain (10.1 W-50.6 E, 19.1 N-54.0 N) covers the Mediterranean and Middle East (see Fig. 2). All data exposed to the regressions are transformed from original ERA40 set to the points of $1.125 \times 1.125$ horizontal grid and to 13 constant height surfaces with constant spacing $D z=1000 \mathrm{~m}$ with the lowest level at $z=500 \mathrm{~m}$ (see Egger and Hoinka 2006 for further details). Similar analyses have been performed for the Atlas range and the Taurus mountains but cannot be discussed here.

Published by Copernicus Publications on behalf of the European Geosciences Union. 


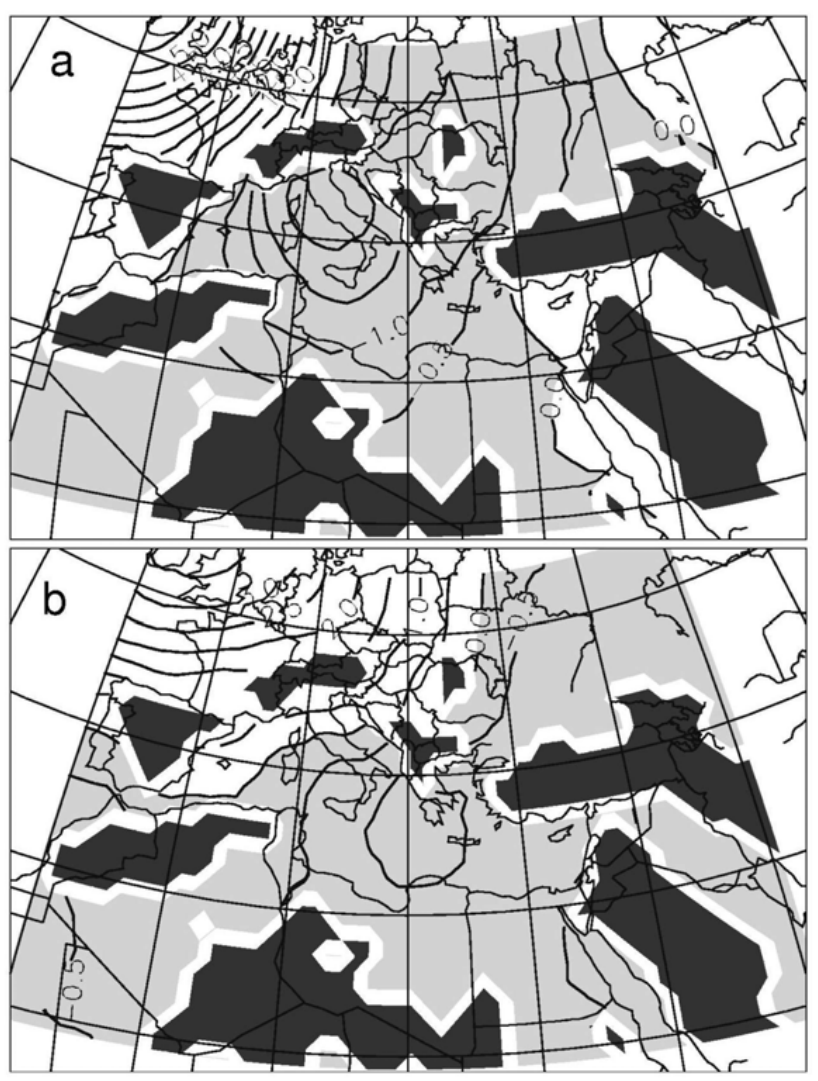

Fig. 1. Covariance $C\left(T_{o 2}^{-}, p \mid \tau\right)$ of the negative $90^{\circ} \mathrm{E}$ Alpine torque with pressure in $\mathrm{hPa}$ in fall at $z=500 \mathrm{~m}$ at (a) $\tau=-1$ day and (b) $\tau=2$ days but with the sign reversed to obtain the "observed" pressure fields; topography dark; contour interval $0.5 \mathrm{hPa}$; negative values shaded.

\section{Results}

We present events with negative torques in fall. The regression of the pressure at the lowest level against the torque $T_{o 2}$ of the Alps is displayed in Fig. 1 for various lags. A rather weak high is seen over the Atlantic at the lag $\tau=-5$ days (not shown) while the pressure anomalies are negative over a wide domain extending from Africa to the Baltic Sea. Amplitudes are less than $1 \mathrm{hPa}$ but grow substantially during the following four days. The Atlantic high moves towards the east and there is continous pressure fall in the lee of the Alps with a closed $-2 \mathrm{hPa}$ isobar in central Italy (Fig. 1a) for $\tau=-1$ day. From then on, this new low is moving eastwards and its amplitude decreases so that there only a weak remnant is seen near Greece at $\tau=2$ days (Fig. 1b). Somewhat higher up $(z=2500 \mathrm{~m})$ a broad trough covers the western Mediterranean (not shown) which is almost stationary till $\tau=-1$ day when a separate low pressure center is found above the Alpine lee. The trough is then moving eastward. This sequence of pressure patterns is reminiscent of the upstream type (Vorderseiten-type) of lee cyclogenesis as de- fined by Pichler and Steinacker (1987). This terminology refers to the fact that "lee cyclogenesis" occurs upstream of the Alps with respect to the upper level-flow.

It is of particular interest to discover the causes for the pressure fall in the lee. After all, many theories of Alpine cyclogenesis have been proposed invoking different mechanisms (see Egger (1988) for a brief review). In principle, changes of the surface pressure at a point are caused by the horizontal divergence of density flux above this point. Although the data for such calculations are available, the data accuracy is not adequate for this purpose. We can, however, infer pressure changes at a level from those of potential temperature above. After all, pressure perturbations $p^{\prime}$ are related to those of potential temperature $\theta^{\prime}$ by

$\frac{\partial p^{\prime}}{\partial z}+A p^{\prime}=B \theta^{\prime}$

where

$A=g \bar{\rho} c_{v} /\left(c_{p} \bar{p}\right)$.

$B=g \bar{\rho} / \bar{\theta}$

and where the bar denotes the climatological mean. Potential temperature perturbations can be predicted via

$$
\frac{\partial}{\partial t} \theta^{\prime}+\bar{v}_{h} \times \nabla \theta^{\prime}+v_{h}^{\prime} \times \nabla \bar{\theta}+\bar{w} \frac{\partial \theta^{\prime}}{\partial z}+w^{\prime} \frac{\partial \bar{\theta}^{\prime}}{\partial z}=0 .
$$

in standard notation where heat sources and nonlinear terms are excluded. Thus

$\frac{\partial}{\partial t} p_{L}^{\prime}=\frac{\partial p_{T}}{\partial t}-\int_{h_{L}}^{h_{T}} B \frac{\partial \theta^{\prime}}{\partial t} d z+\int_{h_{L}}^{h_{T}} A p^{\prime} d z$.

where $p_{L}^{\prime}\left(p_{T}\right)$ is the pressure at the level $z=h_{L}\left(h_{T}\right)$. If the pressure tendency at $z=h_{T}$ is small we can use (7) to calculate the tendency $p_{L}^{\prime}$. This simple procedure is carried out for the covariances $C\left(T_{o 2}, p \mid \tau\right)$, say, of torque and pressure, where the torque leads with lag $\tau$. We have just to replace all perturbations in (3)-(7) by the respective covariances. These are available once a day so that we can, for example, use the covariances at $\tau=-2$ days to predict the pressure change till $\tau=-1$ day by extrapolation of the tendencies over one day. This tendency calculation is, however, difficult below the crest height of the Alps where the calculation of temperature advection at the slopes is fraught with uncertainties. It has been decided, therefore, to perform the "forecasts" for the level $z_{L}=2500 \mathrm{~m}$ which is above the crests in the smoothed orographic profile of the ERA40 set. Moreover, the actual pressure change at $z=2500 \mathrm{~m}$ as displayed in Fig. 2b is fairly similar to that at the surface. The pressure fall in the lee and the increase in the west are also the dominant features of both patterns. The smoothed linear forecast based on horizontal advection of potential temperatures (Fig. 2a) captures the main features of the observations quite well although the 


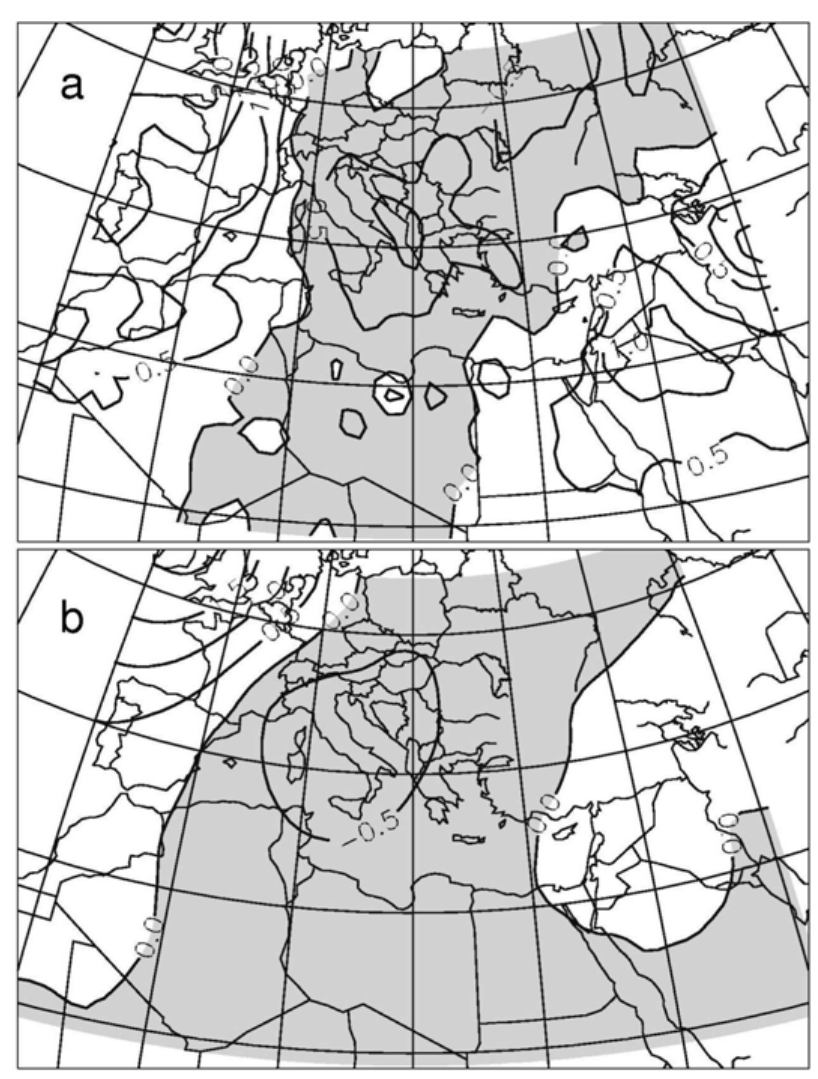

Fig. 2. Difference of the covariance $C\left(T_{o 2}^{-}, p \mid \tau\right)$ at $\tau=-1$ day minus that at $\tau=-2$ days in $\mathrm{hPa}$ in fall at $z_{L}=2500 \mathrm{~m}$ (a) as predicted by Eq. (7) and (b) as observed. The pattern in (a) has been smoothed by a 9 -point smoother; contour interval $0.5 \mathrm{hPa}$.

original pattern is fairly noisy. Inclusion of vertical motion leads to severe overestimation of the tendencies.

All this suggests a relatively simple explanation for the pressure fall in the lee in Fig. 1. Initially there is a quasistationary trough which intensifies. The related warm air advection above the lee side leads to pressure fall and an increase of the torque till $\tau \sim 0$. From then on, the trough is beginning to move eastward because of this pressure fall east of its axis and the torque is beginning to decrease. Similar statements on lee cyclogenesis mechanism have been made since long (e.g. v. Ficker, 1920; Radinovic, 1965). What is new here is the fact that torque events appear to follow generally this path of events. However, the quasistationary behaviour of the trough prior to the maximum torque event is at odds with typical upstream events where the trough moves forcefully into the Mediterranean. We can go one step further and ask which levels contribute most to the pressure fall. It is found that levels above $5000 \mathrm{~m}$ are quite important in inducing the pressure fall.

The related precipitation pattern at $\tau=0$ (Fig. 3 ) shows enhanced rainfall in the Adriatic and the eastern part of the Alps that is, ahead of the trough.

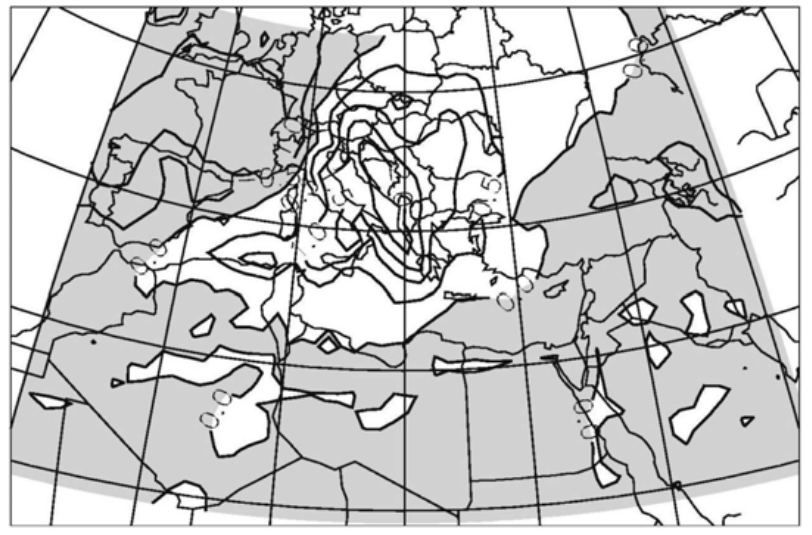

Fig. 3. Covariance $C\left(T_{o 2}^{-}, R \mid \tau\right)$ in fall of the negative Alpine torque $T_{o 2}^{-}$with precipitation in $\mathrm{mm}^{-1} \mathrm{yy}^{-1}$ at $\tau=0$, contour interval 0.5 .

\section{Conclusions}

It has been shown that a regression of atmospheric variables against the negative mountain torque $T_{o 2}^{-}$yields a sequence of pressure maps which is reminiscent of a class of Alpine lee cyclogenesis events termed upstream-type. A linear forecast based on horizontal potential temperatures advection captures the observed pressure changes reasonably well. This indicates that the lee side pressure fall is mainly due to warm air advection aloft ahead of the trough. This mechanism is similar to that invoked since long for an explanation of Alpine lee cyclogenesis but the quasistationarity of the trough as observed during the trough events is not typical of lee cyclogenesis events.

Edited by: P. Alpert, H. Saaroni, and E. Heifetz

Reviewed by: one anonymous referee

\section{References}

Alpert, P., Neeman, B., and Shay-el, Y.: Climatological analysis of Mediterranean cyclones using ECMWF data, Tellus A, 42, 6577, 1990.

Egger, J.: Alpine lee cyclogenesis: Verification of theories, J. Atmos Sci. 45, 2187-2203, 1988.

Egger, J. and Hoinka, K.-P.: Dynamics of atmospheric regression patterns: regional mountain torque events, J. Atmos. Sci., 63, 1467-1482, 2006.

Ficker, H. von: Der Einfluß der Alpen auf Fallgebiete des Luftdrucks und die Entstehung von Depressionen über dem Mittelmeer, Met. Zeitschr., 37, 350-363, 1920.

Lionello, P., Bhend, J, Buzzi, A., Della Marta, P., Krichak, S., Jansa, A., Materas, P., Sanna, A., Trigo, I., and Trigo, R.: Cyclones in the Mediterranean Region: climatology and effects on the environment, in: Mediterranean Climate Variability, edited by: Lionello, P., Malanotte-Rizzoi, P., and Boscolo, B., Elsevier, Amsterdam, 325-397, 2006. 
Pichler, H. and Steinacker, R.: On the synoptics and dynamics of orographically induced cyclones in the Mediterranean, Meteor. Atmos. Phys., 36, 108-117, 1987.
Radinoviæ, D.: On forecasting of cyclogenesis in the West Mediterranean and other areas bounded by mountain range by baroclinic model, Arch. Met. Geophys. Biokl. A ,14, 279-299, 1965. 